OPEN ACCESS

Edited by:

Hariom Yadav

Wake Forest School of Medicine,

United States

Reviewed by:

Avital Schurr.

University of Louisville, United States

Jitender Mehla,

Virginia Commonwealth University,

United States

${ }^{*}$ Correspondence:

Yaping Jin

jinyp@mail.cmu.edu.cn

Specialty section:

This article was submitted to

Neuroenergetics, Nutrition and Brain

Health,

a section of the journa

Frontiers in Neuroscience

Received: 28 August 2017 Accepted: 08 January 2018

Published: 23 January 2018

Citation:

Wang G, Yuan Y, Gao L, Tan X, Yang G, Zhao F and Jin Y (2018)

Disruption of Intracellular ATP Generation and Tight Junction Protein Expression during the Course of Brain

Edema Induced by Subacute

Poisoning of 1,2-Dichloroethane.

Front. Neurosci. 12:12.

doi: 10.3389/fnins.2018.00012

\section{Disruption of Intracellular ATP Generation and Tight Junction Protein Expression during the Course of Brain Edema Induced by Subacute Poisoning of 1,2-Dichloroethane}

\author{
Gaoyang Wang ${ }^{1}$, Yuan Yuan ${ }^{2}$, Lanyue Gao ${ }^{2}$, Xiaoqiong Tan ${ }^{1}$, Guangqian Yang ${ }^{1}$, \\ Fenghong Zhao ${ }^{1}$ and Yaping Jin ${ }^{1 *}$ \\ ${ }^{1}$ Department of Occupational and Environmental Health, School of Public Health, China Medical University, Shenyang, \\ China, ${ }^{2}$ Department of Health Laboratory Technology, School of Public Health, China Medical University, Shenyang, China
}

The aim of this study was to explore changes in intracellular ATP generation and tight junction protein expression during the course of brain edema induced by subacute poisoning of 1,2-dichloroethane (1,2-DCE). Mice were exposed to $1.2 \mathrm{~g} / \mathrm{m}^{3}$ 1,2-DCE for $3.5 \mathrm{~h}$ per day for 1,2 , or 3 days, namely group $\mathrm{A}, \mathrm{B}$, and $\mathrm{C}$. $\mathrm{Na}^{+}-\mathrm{K}^{+}$-ATPase and $\mathrm{Ca}^{2+}$-ATPase activity, ATP and lactic acid content, intracellular free $\mathrm{Ca}^{2+}$ concentration and ZO-1 and occludin expression in the brain were measured. Results of present study disclosed that $\mathrm{Ca}^{2+}$-ATPase activities in group $\mathrm{B}$ and $\mathrm{C}$, and $\mathrm{Na}^{+} / \mathrm{K}^{+}$-ATPase activity in group $\mathrm{C}$ decreased, whereas intracellular free $\mathrm{Ca}^{2+}$ concentrations in group $\mathrm{B}$ and C increased significantly compared with control. Moreover, ATP content decreased, whereas lactic acid content increased significantly in group $\mathrm{C}$ compared with control. On the other hand, expressions of ZO-1 and occludin at both the protein and gene levels in group $\mathrm{B}$ and $\mathrm{C}$ decreased significantly compared with control. In conclusion, findings from this study suggest that calcium overload and depressed expression of tight junction associated proteins, such as ZO-1 and occludin might play an important role in the early phase of brain edema formation induced by subacute poisoning of 1,2-DCE.

Keywords: 1, 2-dichloroethane poisoning, brain edema, ATP generation, blood brain barrier, tight junction associated proteins

\section{INTRODUCTION}

The compound 1,2-dichloroethane (1,2-DCE, CAS number: 107-06-2) is one of the most widely-produced halocarbons, used mainly in the production of vinyl chloride worldwide. This chemical is also used as general organic solvent, especially the thinner of adhesives in some countries. As a volatile organic chemical, 1,2-DCE evaporates quickly into the air, therefore, the primary route of exposure in the workplace is vapor inhalation (Liu et al., 2010; Sun et al., 2016c). It is known that subacute poisoning of 1,2-DCE can cause toxic encephalopathy in exposed workers. Postmortem examinations and clinical studies reported that brain edema was the main pathological change and cause of death among poisoned workers (Zhang et al., 2011; Chen et al., 2015). However, to date, little is known about the mechanisms of 1,2-DCE-induced brain edema. 
Brain edema is commonly classified into cytotoxic and vasogenic types associated with either intracellular or extracellular accumulation of abnormal fluid. The former is due to disordered energy metabolism in injured brain cells, while the latter results from breakdown of the blood brain barrier (Michinaga and Koyama, 2015). It is well-known that intracellular energy metabolism is the process of ATP generation from the nutrients via oxidative phosphorylation in mitochondria. Both $\mathrm{Na}^{+}-\mathrm{K}^{+}$-ATPase and $\mathrm{Ca}^{2+}$-ATPase are the enzymes found in the plasma membrane of all animal cells, where they pump $\mathrm{Na}^{+}$and $\mathrm{Ca}^{2+}$ out of cells while pumping $\mathrm{K}^{+}$into cells against their concentration gradients, using energy provided by ATP hydrolysis. These transporters help maintain high intracellular concentrations of $\mathrm{K}^{+}$and low concentrations of $\mathrm{Ca}^{2+}$ and $\mathrm{Na}^{+}$(Jeremias et al., 2012; Liu et al., 2013). Disordered energy metabolism reduces ATP generation, and impedes activities of plasma membrane ion pumps, which will inevitably lead to excessive increase of intracellular $\mathrm{Na}^{+}$and $\mathrm{Ca}^{2+}$, and finally cause water excess and calcium overload in brain cells, thus forming cytotoxic brain edema (Thrane et al., 2011; Song et al., 2014). It has been reported that recovery of $\mathrm{Na}^{+}-\mathrm{K}^{+}$-ATPase activity coincided with restoration of cerebral edema after brain hypoxia-ischemia (Mintorovitch et al., 1994). Our previous study (Sun et al., 2016b) also reported that exposure to 2-chloroethanol (a metabolite of 1,2-DCE in vivo) could cause decreased activities of $\mathrm{Na}^{+}-\mathrm{K}^{+}$-ATPase and $\mathrm{Ca}^{2+}$-ATPase in astrocytes, which might be related to 1,2-DCE-induced brain edema. Simultaneously, decreased ATP supply from mitochondria will promote anaerobic metabolism in the cytoplasm, leading to accumulation of lactic acid, and in turn, increased permeability of blood brain barrier (Kubota et al., 2012; Bosoi and Rose, 2014).

The blood brain barrier is a diffusion barrier essential for maintenance of normal brain function, which controls influx of most intravascular compounds from the blood into brain. It is composed of endothelial cells, pericytes and end-feet of astrocytes. Among them, endothelial cells are the most critical elements for preventing toxic substances from entering the brain. Endothelial cells are connected by tight junctions, which limit the paracellular flux of hydrophilic molecules across the barrier. Thus, tight junctions between endothelial cells are the most important structural components and crucial for permeability and integrity of the blood brain barrier (Wolburg et al., 2003; Abbott et al., 2010). Tight junctions consist of three integral membrane proteins: claudin, occluding, and junction adhesion molecules. In addition, there are several cytoplasmic accessory proteins including zona occuldens proteins (ZO-1, ZO-2, and $\mathrm{ZO}-3$ ), cingulin and others. ZO-1 and occludin are thought to play the essential roles in maintaining the integrity of blood brain barrier, although there may be additional tight junction associated proteins (Jie et al., 2015). It has been reported that levels of ZO-1 and occludin were significantly altered in many pathological conditions, such as stroke, ischemia, hypoxia, septic encephalopathy, and brain tumors. In most cases, these pathological conditions were associated with breakdown of blood brain barrier and vasogenic cerebral edema (Hawkins et al., 2004; Liu et al., 2008; Jiao et al., 2011; Chen et al., 2012).
The results of our previous study (Wang et al., 2014) showed increased brain water content and enlargement of perinuclear and lacunar spaces surrounding vessels in the brain of mice exposed to $1.2 \mathrm{~g} / \mathrm{m}^{3} 1,2$-DCE for $3.5 \mathrm{~h}$ per day for up to three days, which suggested that a mouse model of brain edema induced by subacute poisoning of 1,2-DCE had been successfully established. Based on this model, the mechanisms underlying brain edema were explored in our previous study, and the results showed that protein expression of aquaporin 4 (AQP4) and mRNA expression of matrix metallopeptidase 9 in the brain were up-regulated in the early phase of brain edema formation. In the present study, alterations of cellular ATP generation and tight junction associated proteins, i.e., occludin and ZO-1, were further explored by using this mouse model of brain edema.

\section{MATERIALS AND METHODS}

\section{Animals}

Female Kunming albino mice weighing between 23 and $26 \mathrm{~g}$ were obtained from the animal laboratory of China Medical University. The animal room was kept at a temperature of $22-$ $24^{\circ} \mathrm{C}$ with a $12 \mathrm{~h} \mathrm{light/dark}$ cycle and a relative humidity of 50$60 \%$. Mice were housed five per cage in the sterilized plastic cages with wood shaving bedding. Except when exposed to inhalants, food, and water were available to animals. During the study, mice were weighed daily and carefully observed for the signs of morbidity and mortality.

This study protocol has been approved by the Scientific Research Committee of China Medical University on Ethics in the Care and Use of Laboratory Animals, and was carried out in accordance with the National Institutes of Health guidelines in a manner that minimized animal suffering and animal numbers.

\section{Experimental Procedures}

After 1-week adaptation, 100 mice were randomly divided into four groups, a control group and three exposure groups, as described in our previous study (Wang et al., 2014). Mice in exposure groups were exposed to $1.2 \mathrm{~g} / \mathrm{m}^{3}$ 1,2-DCE (initial concentration) for $3.5 \mathrm{~h}$ per day for one day (group A), two days (group B) or three days (group C).

\section{Treatment}

Static inhalation exposure was used in this study. Mice from different groups were placed in the static exposure chamber with a capacity of $100 \mathrm{~L}$, five in each chamber. Mice were exposed for $3.5 \mathrm{~h}$ per day for up to 1,2 , or 3 days. Solution of 1,2 DCE with purity of more than $99 \%$ was weighed according to administered concentrations, which were calculated by weight of 1,2-DCE divided by volume of chamber. The compound was placed on a filter paper in a plate suspended in the chamber, and then evaporated by a fan after sealing the chamber. Mice in the control group were kept in chamber without 1,2-DCE exposure. Following exposure, mice were removed from the chambers immediately.

Although it was problematic, static inhalation exposure has its own advantages, including that it is inexpensive, easy to build and operate, and involves less consumption of test chemicals. 
This is particularly suitable for small animals in experiments of acute and subacute inhalation exposure. Data from the U.S. Environmental Protection Agency (1998) and the Chinese Textbook of Toxicology, state that mice consume 1.38 2.22 L per hour of air, indicating that up to 10 mice were permitted in a $100 \mathrm{~L}$ exposure chamber for $4 \mathrm{~h}$. However, in present study, only five mice were kept in $100 \mathrm{~L}$ exposure chamber for $3.5 \mathrm{~h}$. At the end of exposure, the concentration of oxygen was near $20 \%$, carbon dioxide was lower than $1.5 \%$, and humidity was lower than $70 \%$ in the chamber. Moreover, the time-weighted average concentration of 1,2-DCE in the chamber during exposure was $0.99 \mathrm{~g} / \mathrm{m}^{3}$.

\section{Analysis Process}

\section{Activities of $\mathrm{Na}^{+}-\mathrm{K}^{+}$-ATPase and $\mathrm{Ca}^{2+}$-ATPase}

Mice in each group were deeply anesthetized with ether and sacrificed by decapitation one day after the last exposure. The right cerebral hemispheres were removed immediately and homogenized in $0.9 \%$ cold physiological saline. Activities of both $\mathrm{Na}^{+}-\mathrm{K}^{+}$-ATPase and $\mathrm{Ca}^{2+}$-ATPase in cerebral homogenate were spectrophotometrically determined with commercially available kits (Nanjing Jiancheng Bioengineering Institute, China) according to manufacturer's instructions, and defined as the amount of inorganic phosphorus generated by $1 \mathrm{mg}$ protein per hour (expressed as $\mathrm{U} / \mathrm{mg}$ protein).

\section{Contents of ATP and Lactic Acid}

Cerebral homogenates were prepared as above and centrifuged at $12,000 \mathrm{rpm}$ for $10 \mathrm{~min}$. Supernatant was collected and analyzed spectrophotometrically by using the commercial assay kits (Nanjing Jiancheng Biotechnology Institute, China). The contents of ATP and lactic acid in the brain were expressed as $\mu \mathrm{mol} / \mathrm{g}$ protein.

\section{Concentrations of Intracellular Free $\mathrm{Ca}^{2+}$}

The method described previously (Chan et al., 1996) was used in present study. Briefly, cerebral cortex was digested with $0.25 \%$ trypsin (Sigma, USA) at $37^{\circ} \mathrm{C}$ for $20 \mathrm{~min}$. The reaction was terminated with DMEM containing 10\% FBS (Hyclon, USA). Samples were filtered through a cell strainer, and centrifuged at $1,000 \mathrm{rpm}$ for $5 \mathrm{~min}$. The precipitated cells were resuspended in D-Hank's solution and adjusted to $1 \times 10^{6} \mathrm{cells} / \mathrm{ml}$. They were loaded with $5 \mu \mathrm{M}$ fura-2 AM (Sigma, USA) at $37^{\circ} \mathrm{Cfor}$ $30 \mathrm{~min}$ in the dark, washed twice with D-Hank's solution, and incubated at $37^{\circ} \mathrm{C}$ for $5 \mathrm{~min}$ in the dark. Concentrations of intracellular free $\mathrm{Ca}^{2+}\left[\mathrm{Ca}^{2+}\right]$ i were determined by using fluorospectrophotometer (Hitachi F-4500, Japan). The following equation was used for calculation:

$\left[\mathrm{Ca}^{2+}\right] \mathrm{i}=\mathrm{Kd} \times[(\mathrm{R}-\mathrm{Rmin}) /(\mathrm{Rmax}-\mathrm{R})] \times(\mathrm{Sf3} 30 / \mathrm{Sb} 380)$, where $\mathrm{Kd}$ is the dissociation constant of the dye (224 $\mathrm{nM}$ was used); $\mathrm{R}$ is the ratio at excitation wavelengths $340 / 380 \mathrm{~nm}$; $\mathrm{Rmin}$ is the ratio at zero $\left[\mathrm{Ca}^{2+}\right] \mathrm{i}$, and $\mathrm{Rmax}$ is the ratio at saturated $\left[\mathrm{Ca}^{2+}\right] \mathrm{i}$. Rmax was obtained by adding $0.2 \%$ Triton X-100 to make cell membrane permeable to $\mathrm{Ca}^{2+}$, allowing the extracellular and intracellular free $\mathrm{Ca}^{2+}$ to equilibrate. Thereafter, Rmin was determined by adding chelator to erase all extracellular and intracellular free $\mathrm{Ca}^{2+}$. Results were expressed as nmol/L $\left(10^{6}\right.$ cells $/ \mathrm{ml})$.

\section{Immunofluorescence Staining}

Five mice in each group were anesthetized with ether. They were perfused through heart with PBS containing $0.02 \%$ heparin, followed by $4 \%$ paraformaldehyde in PBS. Cerebral cortexes were quickly removed to a cold plate, then fixed overnight in $4 \%$ paraformaldehyde. Fixed samples were immersed in $30 \%$ sucrose for 3 days and embedded in OCT-compound. Serial frozen coronal sections $(8 \mu \mathrm{m})$ were sliced at $-20^{\circ} \mathrm{C}$ using a cryostat microtome. Thereafter, sections were permeabilized for 30 min in PBS containing $0.3 \%$ Triton X-100 and incubated for 30 min with normal goat serum (ZSGB-BIO, Beijing, China) to block nonspecific binding of antiserum.

For immunofluorescence staining, sections were incubated with rabbit antibodies against ZO-1 (Millipore, CA, USA) and occludin (Zymed, MA, USA), and mouse antibody against GFAP (Millipore, CA, USA) at $4^{\circ} \mathrm{C}$ overnight. On the following day, goat anti-rabbit FITC and goat anti-mouse TRITC conjugated secondary antibodies (ZSGB-BIO, Beijing, China), were added and incubated for $30 \mathrm{~min}$ at $37^{\circ} \mathrm{C}$ in a dark room. Finally, the frontoparietal region was observed under a fluorescence microscope (Olympus BX50). Images were captured using a digital camera system (Olympus SC35). The relative fluorescence intensities of ZO-1 and occludin were quantified using image $J$ software (NIH, USA).

\section{Western Blot Analysis}

Cerebral tissues were homogenized in RIPA lysis buffer, and then lysate was centrifuged at $4^{\circ} \mathrm{C}, 12,000 \times \mathrm{g}$ for $20 \mathrm{~min}$. After centrifugation, supernatant was collected for SDS-PAGE. Protein concentrations were measured using BCA protein assay kits (Pierce, IL, USA). An equal amount of protein (45 $\mu \mathrm{g}$ per lane) was subjected to SDS-polyacrylamide gels and separated by electrophoresis. Subsequently, blots were transferred to polyvinylidene difluoride (PVDF) membranes (Millipore, MA, USA), and probed with rabbit antibodies against ZO-1, occludin or $\beta$-actin (Santa Cruz Biotech, Santa Cruz, CA, USA). Membranes were incubated with peroxidase conjugated secondary antibody. Immunoreactive bands were detected with an ECL kit (GE Healthcare, Buckinghamshire, UK). For quantification of immunoblot signals, band intensity was assessed semi-quantitatively by densitometry using an image analyzing software (Gel-Pro analyzer v4.0), and normalized by intensity of $\beta$-actin (as the internal control).

\section{Quantitative Real-time PCR Assay}

Total RNA was extracted from cerebral tissues using Trizol Reagent (Invitrogen, CA, USA). The first strand of cDNA was synthesized from total RNA using PrimeScript RT reagent Kits (Takara, Tokyo, Japan). Thereafter, cDNA was served as templates for real-time PCR amplification using SYBR Premix Ex Taq II (Takara, Tokyo, Japan) and ABI 7500 Real-Time PCR System (Applied Biosystems, CA, USA). To amplify a fragment of ZO-1, occludin and GAPDH (as house-keeping gene), the following primer pairs detailed in Table 1 were used. Amplification was conducted for 40 cycles of $5 \mathrm{~s}$ at $95^{\circ} \mathrm{C}$ and $34 \mathrm{~s}$ at $60^{\circ} \mathrm{C}$. Results were analyzed using the comparative $\mathrm{Ct}$ method as described by Livak and Schmittgen (2001). RNA 
TABLE 1 | Oligonucleotide sequences used for real-time RT-PCR.

\begin{tabular}{llc}
\hline Gene & Primer sequences & Product (bp) \\
\hline ZO-1 & 5'-AAGCGATTCAGCAGCAACAG-3' & 269 \\
& 5'- GGACCGTGTAATGGCAGACT-3' & \\
Occludin & 5'- GCTATGGAGGCTATGGCTATGG-3' & 161 \\
& 5'- CTAAGGAAGCGATGAAGCAGAAG-3' & \\
GAPDH & 5'- CAATGTGTCCGTCGTGGATCT-3' & 124 \\
& $5^{\prime}$ - GTCCTCAGTGTAGCCCAAGATG-3' & \\
\hline
\end{tabular}

abundance was expressed as $2^{-\Delta \Delta C t}$ for target gene normalized against GAPDH gene (as the internal control), and presented as fold-change vs. contralateral control samples.

\section{Statistical Analysis}

Data were expressed as mean \pm standard deviation (SD), and analyzed using SPSS for Windows, version 13.0 (SPSS Inc. IL, USA). Significant difference was evaluated by analysis of variance test (one-way ANOVA). Post hoc tests were analyzed by StudentNewman-Keuls test (SNK). Statistical significance was defined as $P<0.05$.

\section{RESULTS}

\section{General Health of Mice Affected by 1,2-DCE Poisoning}

As described in our previous paper (Wang et al., 2014), mice in group B showed body tremors and forelimb flexure. These signs were more severe in mice of group C. There were no abnormalities in control group during experimental period.

\section{Changes in $\mathrm{Na}^{+}-\mathrm{K}^{+}$-ATPase and $\mathrm{Ca}^{2+}$-ATPase Activity, ATP And Lactic Acid Content in the Brain Induced by 1,2-DCE Poisoning}

To explore changes in intracellular ATP generation in the brain of mice induced by 1,2 -DCE poisoning, $\mathrm{Na}^{+}-\mathrm{K}^{+}$-ATPase and $\mathrm{Ca}^{2+}$-ATPase activities, ATP and lactic acid contents in mouse brain were determined. As shown in Figure 1, $\mathrm{Na}^{+}$$\mathrm{K}^{+}$-ATPase activity in group $\mathrm{C}$, and $\mathrm{Ca}^{2+}$-ATPase activities in group $\mathrm{B}$ and $\mathrm{C}$ decreased significantly $(P<0.05)$ compared with control. Moreover, compared with control, ATP content decreased significantly $(P<0.05)$, whereas lactic acid content increased significantly $(P<0.05)$ in group $C$. On the other hand, as shown in Figure 2, intracellular free $\mathrm{Ca}^{2+}$ concentrations in group $\mathrm{B}$ and $\mathrm{C}$ also increased significantly $(P<0.05)$ compared with control.

\section{Changes in ZO-1 and Occludin Expression in the Brain Induced by 1,2-DCE Poisoning}

Figures 3a, 4a show representative micrographs illustrating immunereactivity of ZO-1 and occludin in the brain, captured on different exposure days. There was continuous expression of $\mathrm{ZO}-1$ and occludin in cerebral tissues in the control group, surrounded by GFAP-positive astroglia processes. However, expression of both ZO-1 and occludin in exposure groups, especially in group $\mathrm{B}$ and $\mathrm{C}$ appeared discontinuously. Furthermore, as shown in Figures $\mathbf{3 b}, \mathbf{4 b}$, compared with control, fluorescence intensities of $\mathrm{ZO}-1$ and occludin in group $\mathrm{B}$ and $\mathrm{C}$ significantly decreased $(P<0.05)$.

Figures 5a, 6a show typical western blots for $\mathrm{ZO}-1$ and occludin. Figures $\mathbf{5 b}$, $\mathbf{6 b}$ disclosed the quantitative analysis of protein blots. Consistent with the results of immunoreactivity, protein levels of both ZO-1 and occludin in group B and $\mathrm{C}$ decreased significantly $(P<0.05)$ compared with control. Additionally, graphs shown in Figures 5c, 6c disclosed quantitative analysis of mRNA expression, which demonstrated that mRNA levels of both ZO-1 and occludin in group B and $\mathrm{C}$ decreased significantly $(P<0.05)$ compared with control.

\section{DISCUSSION}

According to the results we reported previously (Wang et al., 2014), a mouse model of brain edema could be established by exposure to $1.2 \mathrm{~g} / \mathrm{m}^{3}$ 1,2-DCE, $3.5 \mathrm{~h}$ per day for up to 3 days. The results in the present study showed decreased ATP levels and ATPase activities after 1,2-DCE exposure. On one hand, reduced ATP levels may be due to mitochondrial dysfunction or decreased oxygen supply induced by 1,2-DCE poisoning, which may contribute to decreased activities of these pumps since the energy derived from ATP hydrolysis is needed when the cells pump out $\mathrm{Na}^{+}$and $\mathrm{Ca}^{2+}$ against their concentration gradients. On the other hand, decreased activities of the pumps may lead to excessive increase of intracellular $\mathrm{Na}^{+}$and $\mathrm{Ca}^{2+}$, which may cause mitochondrial dysfunction and subsequently result in reduced ATP generation. In addition, the results in the present study suggested that suppressed $\mathrm{Ca}^{2+}$-ATPase activity might occur and lead to calcium overload in the early phase of 1,2-DCE-induced brain edema, since alterations of $\mathrm{Ca}^{2+}$. ATPase and intracellular free $\mathrm{Ca}^{2+}$ appeared earlier than other indicators after 1,2-DCE exposure. It is generally accepted that $\mathrm{Ca}^{2+}$-ATPase transports free $\mathrm{Ca}^{2+}$ into endoplasmic reticulum and out of the cell from cytoplasm using energy obtained through ATP hydrolysis. Thus, suppressed $\mathrm{Ca}^{2+}$-ATPase activity might result in excessive levels of cytoplasm free $\mathrm{Ca}^{2+}$, which could induce a series of catastrophic enzymatic processes, culminating in mitochondrial dysfunction (Putney, 2003) and certain brain pathologies (Paluzzi et al., 2007; Thrane et al., 2011; Song et al., 2014).

Therefore, our results suggest that exposure to 1,2-DCE might disturb calcium homeostasis in brain cells, thereby causing an energy metabolism disorder (Liu et al., 2013; Rosa et al., 2015; Vlodavsky et al., 2017). It has been reported by Wang et al. (2007) that treatment with 1,2-DCE could increase the concentration of calcium in rat neurons, which was consistent with our results. Similarly, in our previous study (Sun et al., 2016b), primary cultured astrocytes were exposed to different levels of 2-CE, and the result showed inhibited activities of $\mathrm{Na}^{+}-\mathrm{K}^{+}$-ATPase and $\mathrm{Ca}^{2+}$-ATPase in the cells, which is consistent with our present in vivo results. 


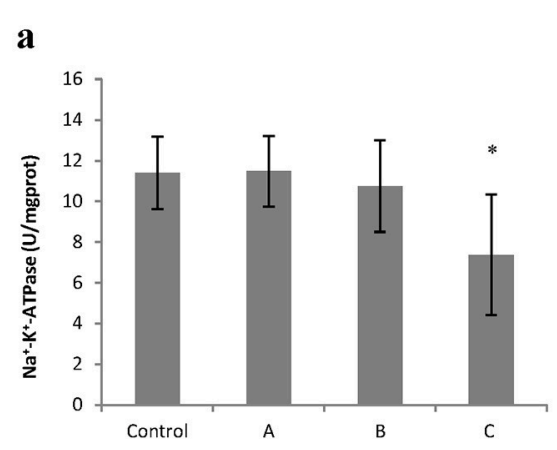

b
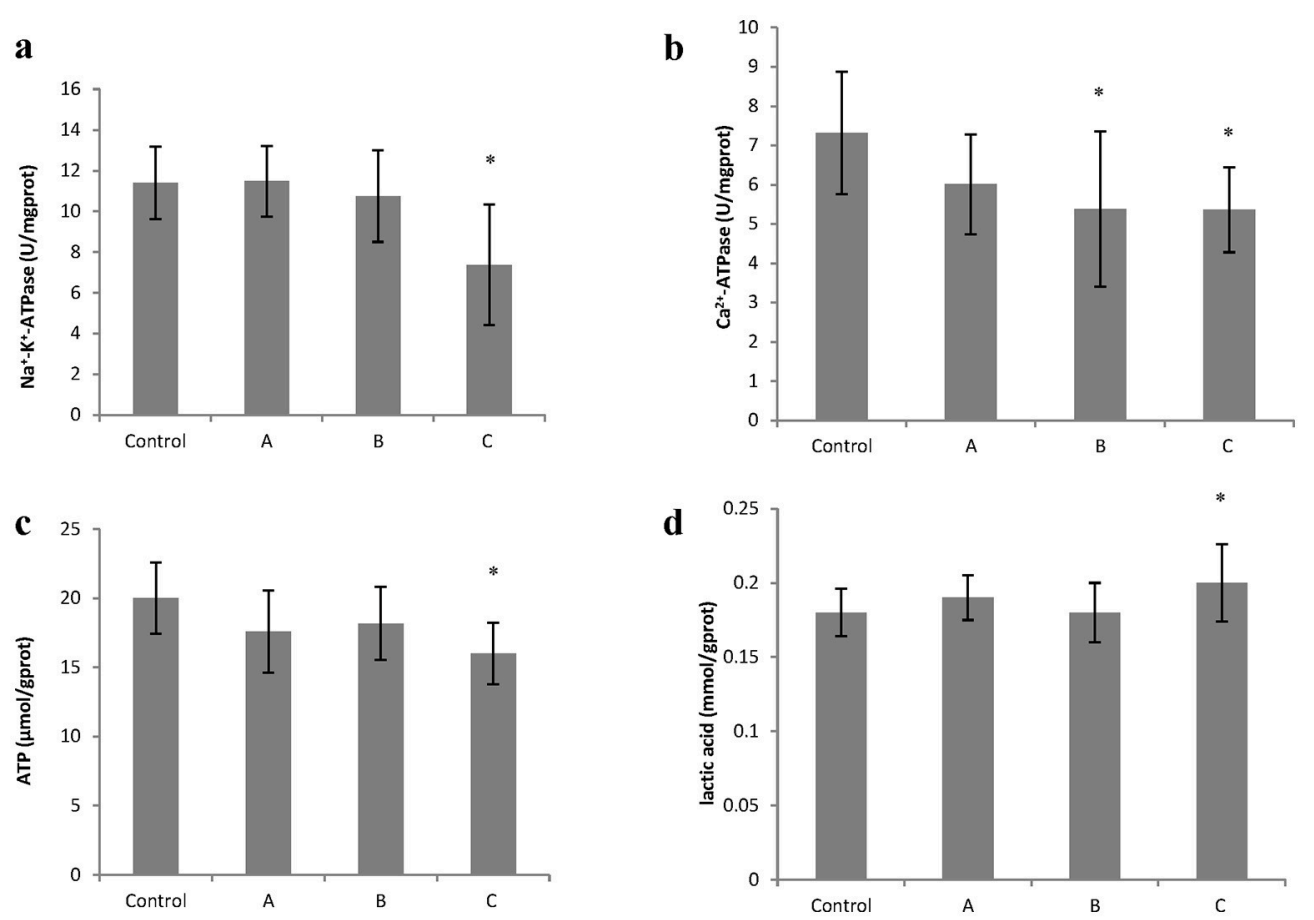

FIGURE 1 | Changes in $\mathrm{Na}^{+-} \mathrm{K}^{+}$-ATPase and $\mathrm{Ca}^{2+}$-ATPase activity, ATP and lactic acid content in mouse brain cells induced by subacute poisoning of 1,2-DCE. (a) Comparison of $\mathrm{Na}^{+}-\mathrm{K}^{+}$-ATPase activity in mouse brain cells among groups; (b) Comparison of Ca ${ }^{2+}$-ATPase activity in mouse brain cells among groups; (c) Comparison of ATP content in mouse brain among groups. (d) Comparison of lactic acid level in mouse brain among groups. The number of mice were 10 in control group, 9 in group A, 8 in group B, and 8 in group C. Data were given as mean $\pm S D$, and analyzed by One-way ANOVA. Significant difference was defined as $P<0.05$. * vs. control group.

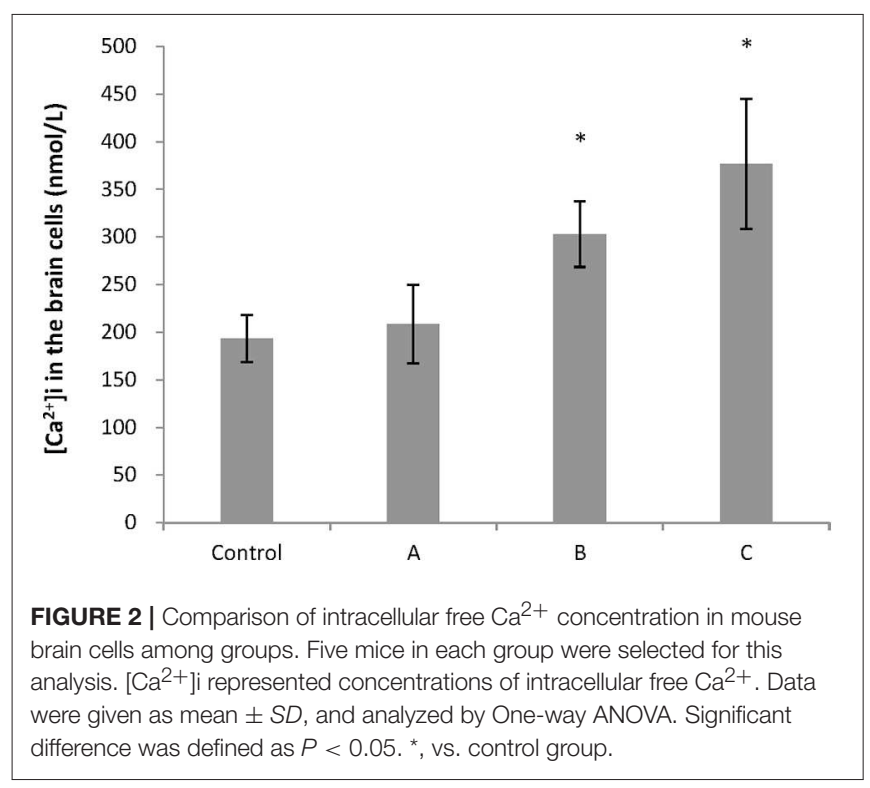

Additionally, it is wellknown that lactic acid is the energy source for neurons in the brain. In injured neurons, less lactic acid may be consumed, leading to accumulation of lactic acid in the brain (Preuss, 2012; Bosoi and Rose, 2014). Nevertheless, intracellular contents of ATP and lactic acid are the important indicators of energy metabolism in the brain (Borutaite, 2010; Dienel, 2014). Though disordered energy metabolism is the main cause of cytotoxic edema in the brain, it might also result in vasogenic brain edema since increased levels of intracellular lactic acid induced by cytotoxic edema might disturb the function of the blood brain barrier (Chen et al., 2000; Rose, 2010; Yang et al., 2012; Afadlal et al., 2014). Therefore, although brain edema can be divided into cytotoxic and vasogenic edema at the initial stage, given that cytotoxic and vasogenic edema can be the cause of each other, it will become mixed brain edema soon.

Occludin, an integral protein at the tight junctions has four transmembrane domains, two extracellular loops and one intracellular loop (Fusco and Paluzzi, 1993). Among them, the extracellular loops originated from the neighboring cells form the paracellular barrier of tight junctions. The cytoplasmic domain is directly associated with $\mathrm{ZO}$ proteins for assembly of occludin into tight junctions. It has been reported that occludin is the most reliable immunohistochemical marker for tight junctions, reflecting structural integrity of blood brain barrier (Wells and Bonetta, 2005; Wen et al., 2014). ZO-1 belongs to the family of proteins known as membrane-associated guanylate kinaselike protein. It contains three PDZ domains, one SH3 domain and one guanyl kinase like domain. It has been reported that the guanylate kinase-like domain interacts with occludin, and the C-terminal binds to actin, forming a scaffold to anchor 


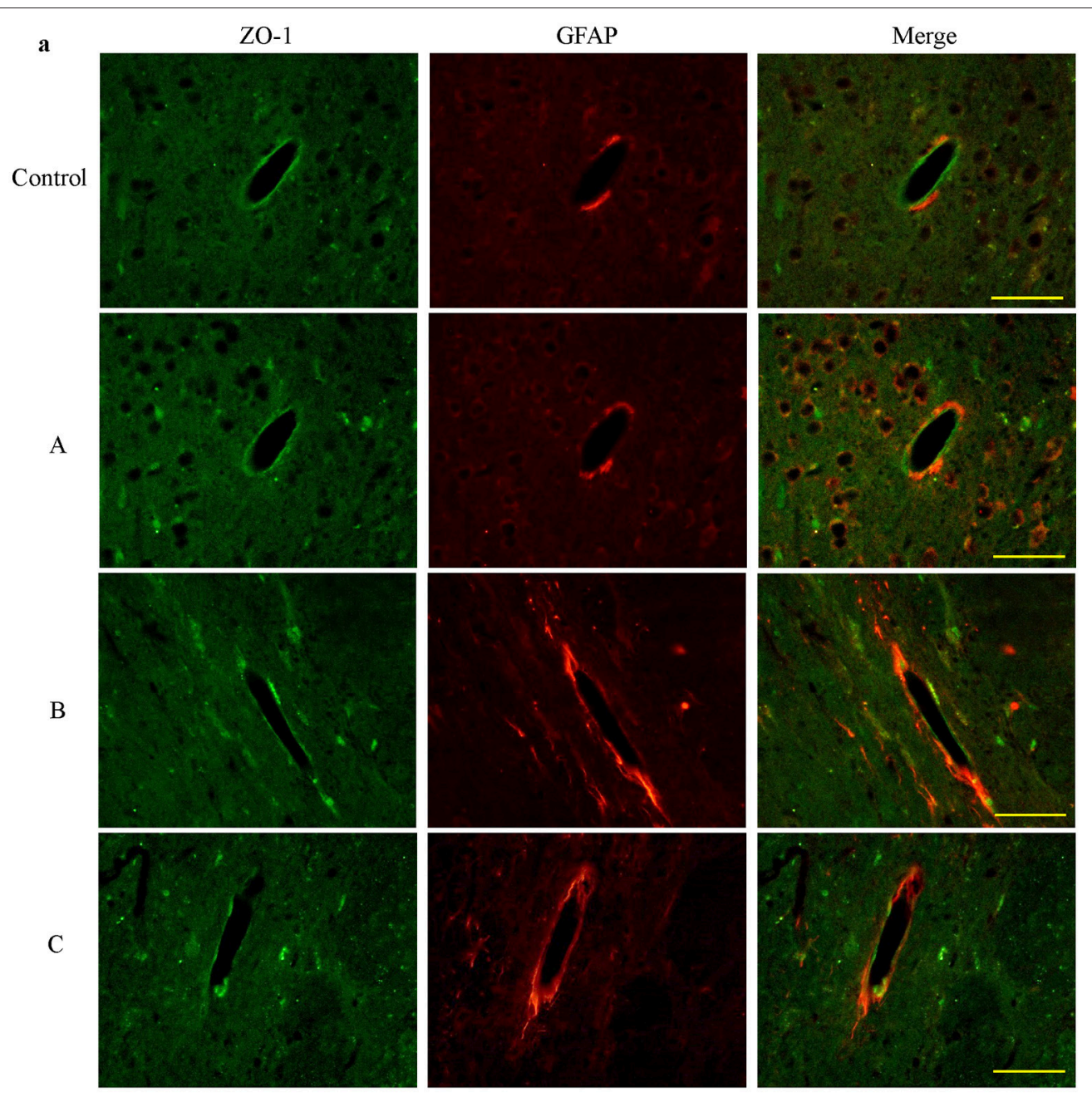

b

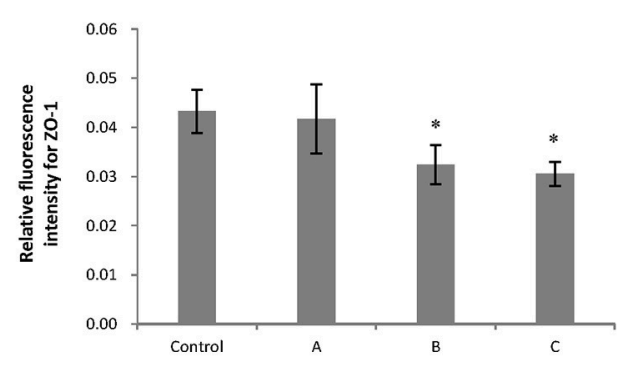

FIGURE 3 | Comparison of ZO-1 protein expression in mouse brain among groups (scale bar $=25 \mu \mathrm{m}$ ). Five mice were selected in each group. Data were given as mean $\pm S D$, and analyzed by one-way ANOVA. Significant difference was defined as $P<0.05$, * vs. control group. (a) Immunofluorescence staining, green represented ZO-1, and red is for GFAP. A to C represented three exposure groups, in which mice were exposed to 1,2-DCE for 1, 2, or 3days. (b) Comparison of relative fluorescence intensity for $\mathrm{ZO}-1$ among groups.

transmembrane proteins to the cytoskeleton in epithelial cells (Kojima et al., 2013). Based on the studies done so far, it is thought that both ZO-1 and occludin are essential for the integrity of the blood brain barrier (Jiao et al., 2011; Li et al., 2014; Mohamed Mokhtarudin and Payne, 2015).

Findings from this study demonstrated that both protein and gene levels of occludin and ZO-1 in the brain decreased apparently after two exposure days, suggesting that loss of tight junction associated proteins might occur at the early phase of 1,2-DCE- induced brain edema. In addition, our results suggest that expression of both ZO-1 and occludin were downregulated at the transcriptional level in 1,2-DCE poisoned mice. Although the mechanisms concerning regulation of tight junction associated proteins are not completely understood, 


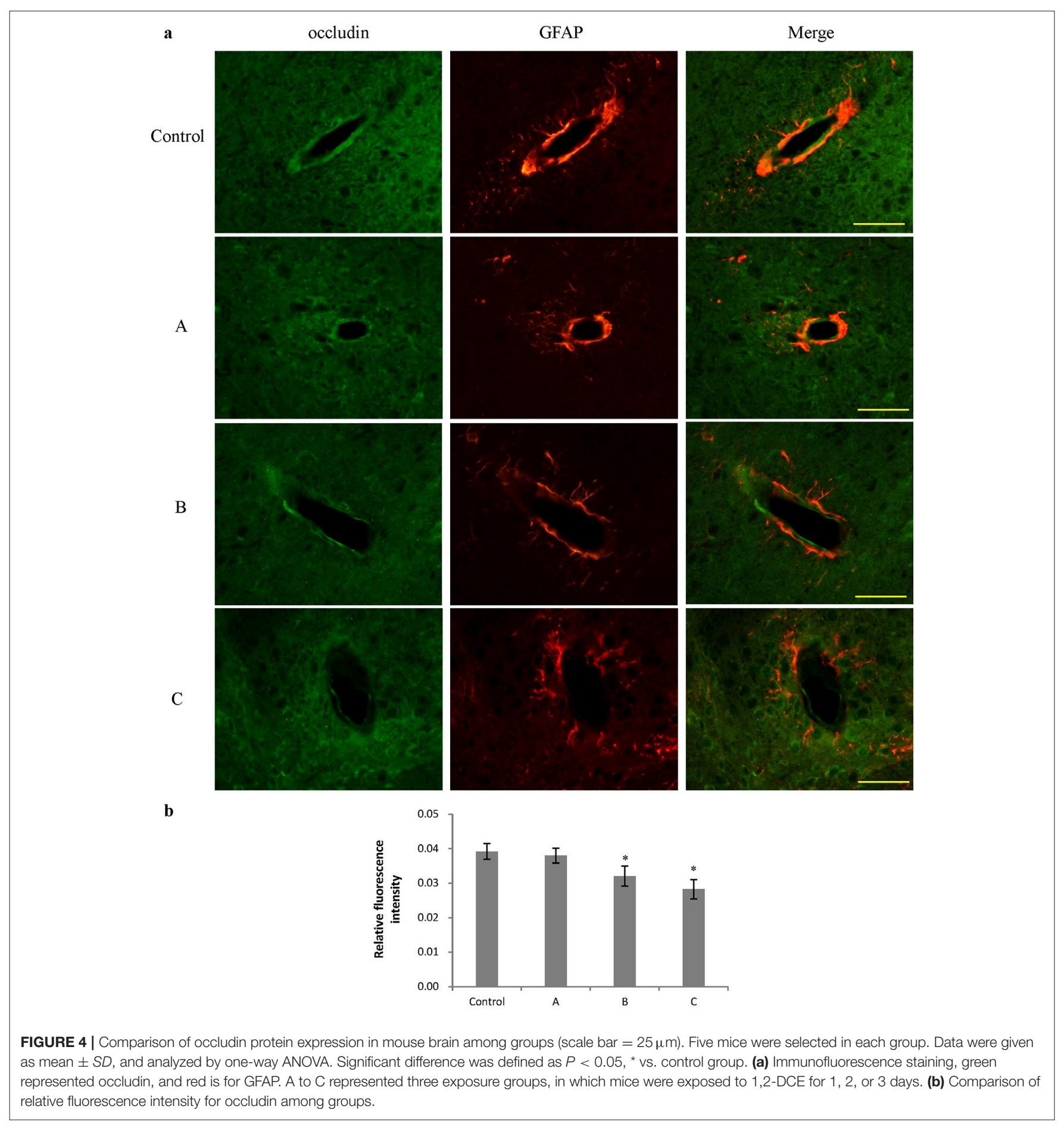

it is known that there are two principal signal transduction pathways: signals transduced from the cell interior to guide tight junction assembly, and signals transmitted from tight junctions to the cell interior to modulate gene expression. Multiple elements including $\mathrm{Ca}^{2+}$, protein kinase $\mathrm{A}$ and $\mathrm{C}, \mathrm{G}$ protein and calmodulin, may be implicated in these processes. Among them, $\mathrm{Ca}^{2+}$ can act both intracellularly and extracellularly to regulate tight junctions. It has been reported that intracellular free $\mathrm{Ca}^{2+}$ plays a role in trans-endothelial resistance as well as in ZO-1 migration from intracellular sites to the plasma membrane (Brown and Davis, 2002). Saitou et al. (2000) reported that calcium deposits accumulated progressively in the cerebellum and basal ganglia in occludin -/- mice, and the small granular calcium deposits were often localized along small vessels, mainly 
a

ZO-1 (260 KDa)

$\beta$-actin (43 KDa)
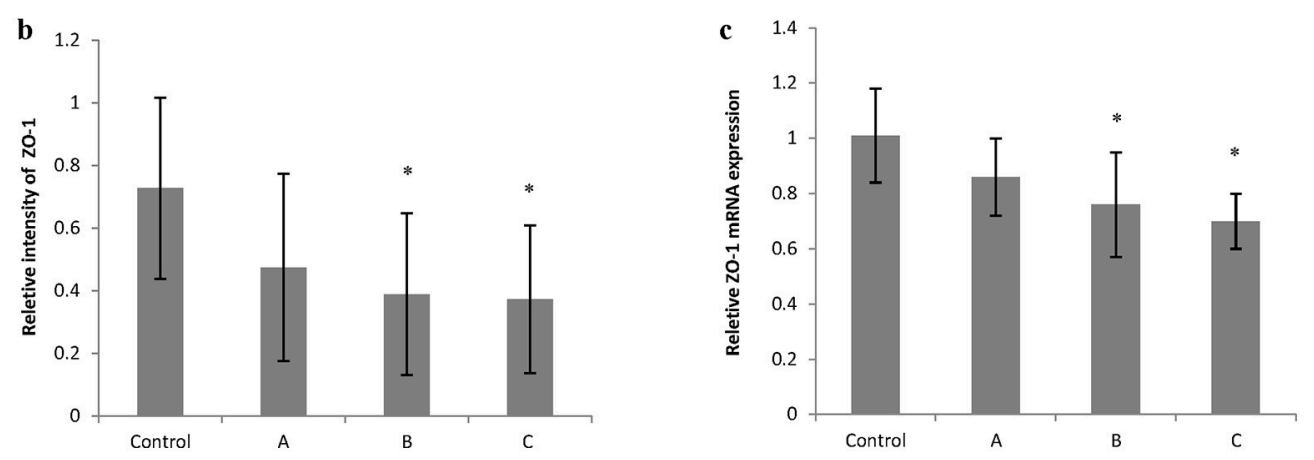

FIGURE 5 | Comparison of ZO-1 protein and mRNA levels in mouse brain among groups. The number of mice used for Western blots and real-time RT-PCR were 10 in control, 9 in group A, 8 in group B, and 8 in group C. Data were given as mean $\pm S D$, and analyzed by one-way ANOVA. Significant difference was defined as $P<0.05$, * vs. control group. (a) Western blot analysis; (b) Densitometric analysis of Western blots; (c) Quantitation of mRNA by real-time RT-PCR. The mRNA levels were normalized to GAPDH and presented as fold change vs. control group.

a

occludin $(59 \mathrm{KDa})$

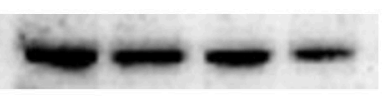

$\beta-\operatorname{actin}(43 \mathrm{KDa})$
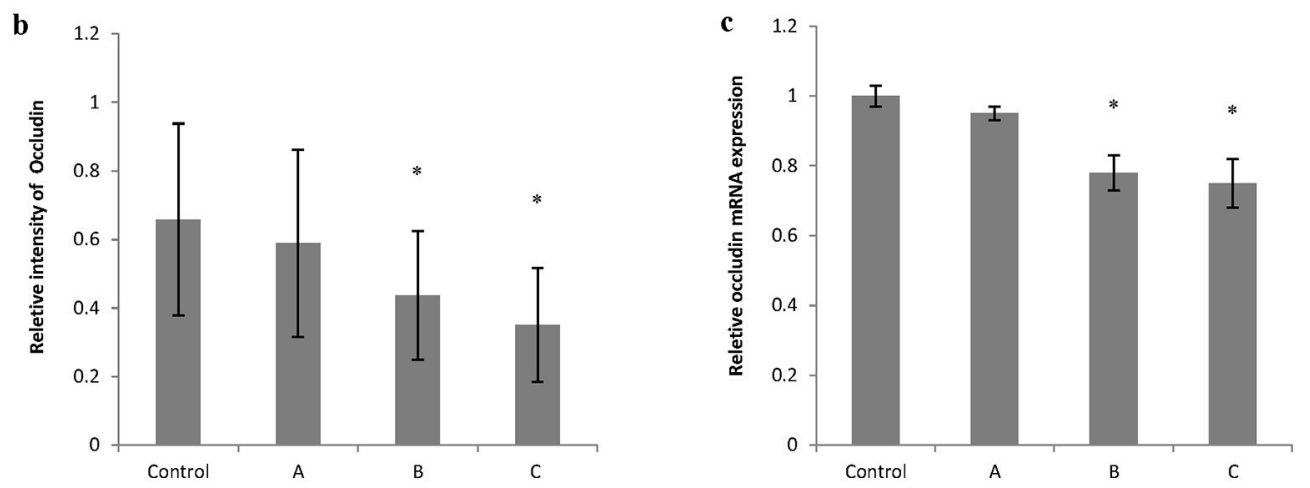

FIGURE 6 | Comparison of occludin protein and mRNA levels in mouse brain among groups. The number of mice used for Western blots and real-time RT-PCR were 10 in control, 9 in group A, 8 in group B, and 8 in group C. Data were given as mean $\pm S D$, and analyzed by one-way ANOVA. Significant difference was defined as $P<0.05$, * vs. control group. (a) Western blot analysis; (b) Densitometric analysis of Western blots; (c) Quantitation of mRNA by real-time RT-PCR. The mRNA levels were normalized to GAPDH and presented as fold change vs. control group.

venules and capillaries, suggesting that occludin was tightly associated with uptake and transport of free $\mathrm{Ca}^{2+}$. Extracellular calcium is also necessary for the homotypic interactions of Ecadherin, which is believed to be the initial event of junctional complex formation. When extracellular calcium is removed, there is a concurrent decrease in transmembrane electrical resistance and an increase in permeability (Huber et al., 2001). Therefore, in this study, it could be hypothesized that downregulated gene and protein expression of both occludin and ZO-1 might contribute, at least in part, to depressed activity 
of $\mathrm{Ca}^{2+}$-ATPase, which could lead to enhanced concentration of intracellular free $\mathrm{Ca}^{2+}$. The accumulated results in our laboratory have demonstrated that up-regulated expression of MMP-9 and AQP4, and down-regulated expression of tight junction proteins, such as ZO-1 and occludin could be induced by 1,2-DCE poisoning during the course of brain edema. It is well known that up-regulated expression of MMP-9 could contribute to disruption of the blood brain barrier integrity. Moreover, findings from our studies have disclosed that activated Mitogen Activated Protein Kinase (MAPK) signal pathways were implicated in the modulation of proinflammatory factors, such as MMPs, iterleukins and tumor necrosis factor, AQPs, tight junction proteins during course of brain edema induced 1,2-DCE poisoning (Sun et al., 2016a; Wang et al., 2017).

Taken together, our data suggest that calcium overload and downregulated expression of tight junction associated proteins, such as occludin and ZO-1 might be the primary events occurring in the early phase of brain edema induced by subacute poisoning of 1,2-DCE. Accordingly, it was reasonable to speculate that brain edema might ensue from disordered intracellular calcium homeostasis and loss of tight junction associated proteins. Nevertheless, at present we could not address clearly how 1,2DCE poisoning resulted in these alterations. Further studies are needed to provide us with clues to clarify the pathogenesis underlying 1,2-DCE-induced brain edema.

\section{REFERENCES}

Abbott, N. J., Patabendige, A. A., Dolman, D. E., Yusof, S. R., and Begley, D. J. (2010). Structure and function of the blood-brain barrier. Neurobiol. Dis. 37, 13-25. doi: 10.1016/j.nbd.2009.07.030

Afadlal, S., Labetoulle, R., and Hazell, A. S. (2014). Role of astrocytes in thiamine deficiency. Metab. Brain Dis. 29, 1061-1068. doi: 10.1007/s11011-01 4-9571-y

Borutaite, V. (2010). Mitochondria as decision-makers in cell death. Environ. Mol. Mutagen. 51, 406-416. doi: 10.1002/em.20564

Bosoi, C. R., and Rose, C. F. (2014). Elevated cerebral lactate: implications in the pathogenesis of hepatic encephalopathy. Metab. Brain Dis. 29, 919-925. doi: 10.1007/s11011-014-9573-9

Brown, R. C., and Davis, T. P. (2002). Calcium modulation of adherens and tight junction function: a potential mechanism for blood-brain barrier disruption after stroke. Stroke 33, 1706-1711. doi: 10.1161/01.STR.0000016405. 06729.83

Chan, E., Yung, W. H., and Baumann, K. I. (1996). Cytoplasmic $\mathrm{Ca}^{2+}$ concentrations in intact Merkel cells of an isolated, functioning rat sinus hair preparation. Exp. Brain Res. 108, 357-366. doi: 10.1007/BF00227259

Chen, S., Zhang, Z., Lin, H., Chen, Z., Wang, Z., and Wang, W. (2015). 1,2dichloroethane-induced toxic encephalopathy: a case series with morphological investigations. J. Neurol. Sci. 351, 36-40. doi: 10.1016/j.jns.2015.02.020

Chen, T., Qian, Y. Z., Di, X., Zhu, J. P., and Bullock, R. (2000). Evidence for lactate uptake after rat fluid percussion brain injury. Acta Neurochir. Suppl. 76, 359-364. doi: 10.1007/978-3-7091-6346-7_75

Chen, X., Threlkeld, S. W., Cummings, E. E., Juan, I., Makeyev, O., Besio, W. G., et al. (2012). Ischemia-reperfusion impairs blood-brain barrier function and alters tight junction protein expression in the ovine fetus. Neuroscience 226, 89-100. doi: 10.1016/j.neuroscience.2012.08.043

Dienel, G. A. (2014). Lactate shuttling and lactate use as fuel after traumatic brain injury: metabolic considerations. J. Cereb. Blood Flow Metab. 34, 1736-1748. doi: $10.1038 /$ jcbfm. 2014.153

\section{AUTHOR CONTRIBUTIONS}

GW: designed, performed, and interpreted the experiments and wrote the manuscript; YY: performed parts of biochemistry experiments and edited the manuscript; LG, XT, GY, and FZ: edited the manuscript; YJ: conceived the study, designed, and interpreted experiments and revised the manuscript. Authors listed in this paper participated in the design, execution, and analysis of this paper. All other authors have read the manuscript and have agreed to submit it in its current form for consideration for publication in the Journal.

\section{FUNDING}

Contract grant sponsor: National Natural Science Foundation of China (NSFC 81172644, 81573105); Program for Liaoning Excellent Talents in University (LR2013038); Program for Liaoning Innovative Research Team in University (LT2015028).

\section{ACKNOWLEDGMENTS}

This work was supported by the grants of National Natural Science Foundation of China (NSFC 81172644, 81573105); Program for Liaoning Excellent Talents in University (LR2013038); Program for Liaoning Innovative Research Team in University (LT2015028).

Fusco, M. A., and Paluzzi, M. W. (1993). Abdominal wall recurrence after laparoscopic-assisted colectomy for adenocarcinoma of the colon. Report of a case. Dis. Colon Rectum 36, 858-861. doi: 10.1007/BF02047384

Hawkins, B. T., Abbruscato, T. J., Egleton, R. D., Brown, R. C., Huber, J. D., Campos, C. R., et al. (2004). Nicotine increases in vivo blood-brain barrier permeability and alters cerebral microvascular tight junction protein distribution. Brain Res. 1027, 48-58. doi: 10.1016/j.brainres.2004.08.043

Huber, J. D., Egleton, R. D., and Davis, T. P. (2001). Molecular physiology and pathophysiology of tight junctions in the blood-brain barrier. Trends Neurosci. 24, 719-725. doi: 10.1016/S0166-2236(00)02004-X

Jeremias, I. C., Scaini, G., Constantino, L., Vuolo, F., Ferreira, A. K., Scherer, E. B., et al. (2012). The decrease on $\mathrm{Na}^{+}, \mathrm{K}^{+}$-ATPase activity in the cortex, but not in hippocampus, is reverted by antioxidants in an animal model of sepsis. Mol. Neurobiol. 46, 467-474. doi: 10.1007/s12035-0128297-2

Jiao, H., Wang, Z., Liu, Y., Wang, P., and Xue, Y. (2011). Specific role of tight junction proteins claudin-5, occludin, and ZO-1 of the blood-brain barrier in a focal cerebral ischemic insult. J. Mol. Neurosci. 44, 130-139. doi: 10.1007/s12031-011-9496-4

Jie, P., Tian, Y., Hong, Z., Li, L., Zhou, L., Chen, L., et al. (2015). Blockage of transient receptor potential vanilloid 4 inhibits brain edema in middle cerebral artery occlusion mice. Front. Cell. Neurosci. 9:141. doi: 10.3389/fncel.2015.00141

Kojima, T., Go, M., Takano, K., Kurose, M., Ohkuni, T., Koizumi, J., et al. (2013). Regulation of tight junctions in upper airway epithelium. Biomed. Res. Int. 2013:947072. doi: 10.1155/2013/947072

Kubota, M., Chida, J., Hoshino, H., Ozawa, H., Koide, A., Kashii, H., et al. (2012). Thermolabile CPT II variants and low blood ATP levels are closely related to severity of acute encephalopathy in Japanese children. Brain Dev. 34, 20-27. doi: 10.1016/j.braindev.2010.12.012

Li, H., Gao, A., Feng, D., Wang, Y., Zhang, L., Cui, Y., et al. (2014). Evaluation of the protective potential of brain microvascular endothelial cell autophagy on blood-brain barrier integrity during experimental 
cerebral ischemia-reperfusion injury. Transl. Stroke Res. 5, 618-626. doi: 10.1007/s12975-014-0354-x

Liu, J. R., Fang, S., Ding, M. P., Chen, Z. C., Zhou, J. J., Sun, F., et al. (2010). Toxic encephalopathy caused by occupational exposure to 1,2-Dichloroethane. J. Neurol. Sci. 292, 111-113. doi: 10.1016/j.jns.2010.01.022

Liu, L. B., Xue, Y. X., Liu, Y. H., and Wang, Y. B. (2008). Bradykinin increases blood-tumor barrier permeability by down-regulating the expression levels of ZO-1, occludin, and claudin-5 and rearranging actin cytoskeleton. J. Neurosci. Res. 86, 1153-1168. doi: 10.1002/jnr.21558

Liu, X., Yue, R., Zhang, J., Shan, L., Wang, R., and Zhang, W. (2013). Neuroprotective effects of bacopaside I in ischemic brain injury. Restor. Neurol. Neurosci. 31, 109-123. doi: 10.3233/RNN-120228

Livak, K. J., and Schmittgen, T. D. (2001). Analysis of relative gene expression data using real-time quantitative PCR and the 2(-Delta Delta C(T)) Method. Methods 25, 402-408. doi: 10.1006/meth.2001.1262

Michinaga, S., and Koyama, Y. (2015). Pathogenesis of brain edema and investigation into anti-edema drugs. Int. J. Mol. Sci. 16, 9949-9975. doi: 10.3390/ijms16059949

Mintorovitch, J., Yang, G. Y., Shimizu, H., Kucharczyk, J., Chan, P. H., and Weinstein, P. R. (1994). Diffusion-weighted magnetic resonance imaging of acute focal cerebral ischemia: comparison of signal intensity with changes in brain water and $\mathrm{Na}^{+}, \mathrm{K}^{(+)}$-ATPase activity. J. Cereb. Blood Flow Metab. 14, 332-336. doi: 10.1038/jcbfm.1994.40

Mohamed Mokhtarudin, M. J., and Payne, S. J. (2015). Mathematical model of the effect of ischemia-reperfusion on brain capillary collapse and tissue swelling. Math. Biosci. 263, 111-120. doi: 10.1016/j.mbs.2015.02.011

Paluzzi, S., Alloisio, S., Zappettini, S., Milanese, M., Raiteri, L., Nobile, M., et al. (2007). Adult astroglia is competent for $\mathrm{Na}^{+} / \mathrm{Ca}^{2+}$ exchanger-operated exocytotic glutamate release triggered by mild depolarization. J. Neurochem. 103, 1196-1207. doi: 10.1111/j.1471-4159.2007.04826.x

Preuss, M. (2012). An energy-failure based brain edema concept. Med. Hypotheses 79, 259-260. doi: 10.1016/j.mehy.2012.05.003

Putney, J. W., Jr. (2003). Capacitative calcium entry in the nervous system. Cell Calcium 34, 339-344. doi: 10.1016/S0143-4160(03)00143-X

Rosa, L., Galant, L. S., Dall'Igna, D. M., Kolling, J., Siebert, C., Schuck, P. F., et al. (2015). Cerebral oedema, blood-brain barrier breakdown and the decrease in $\mathrm{Na}, \mathrm{K}$-ATPase activity in the cerebral cortex and hippocampus are prevented by dexamethasone in an animal model of maple syrup urine disease. $\mathrm{Mol}$ Neurobiol. 53, 3714-3723. doi: 10.1007/s12035-015-9313-0.

Rose, C. F. (2010). Increase brain lactate in hepatic encephalopathy: cause or consequence? Neurochem. Int. 57, 389-394. doi: 10.1016/j.neuint.2010.06.012

Saitou, M., Furuse, M., Sasaki, H., Schulzke, J. D., Fromm, M., Takano, H., et al. (2000). Complex phenotype of mice lacking occludin, a component of tight junction strands. Mol. Biol. Cell 11, 4131-4142. doi: 10.1091/mbc.11. 12.4131

Song, D., Xu, J., Du, T., Yan, E., Hertz, L., Walz, W., et al. (2014). Inhibition of brain swelling after ischemia-reperfusion by beta-adrenergic antagonists: correlation with increased $\mathrm{K}+$ and decreased $\mathrm{Ca}^{2+}$ concentrations in extracellular fluid. Biomed Res. Int. 2014:873590. doi: 10.1155/2014/873590

Sun, Q., Liao, Y., Wang, T., Tang, H., Wang, G., Zhao, F., et al. (2016a). 2Chloroethanol induced upregulation of matrix metalloproteinase-2 in primary cultured rat astrocytes via MAPK signal pathways. Front. Neurosci. 10:593. doi: 10.3389/fnins.2016.00593

Sun, Q., Liao, Y., Wang, T., Wang, G., Zhao, F., and Jin, Y. (2016b). Alteration in mitochondrial function and glutamate metabolism affected by 2-chloroethanol in primary cultured astrocytes. Toxicol. In Vitro 37, 50-60. doi: 10.1016/j.tiv.2016.09.005
Sun, Q., Wang, G., Gao, L., Shi, L., Qi, Y., Lv, X., et al. (2016c). Roles of CYP2e1 in 1,2-dichloroethane-induced liver damage in mice. Environ Toxicol. 31, 1430-1438. doi: 10.1002/tox.22148

Thrane, A. S., Rappold, P. M., Fujita, T., Torres, A., Bekar, L. K., Takano, T., et al. (2011). Critical role of aquaporin-4 (AQP4) in astrocytic $\mathrm{Ca}^{2+}$ signaling events elicited by cerebral edema. Proc. Natl. Acad. Sci. U.S.A. 108, 846-851. doi: 10.1073/pnas.1015217108

U.S. Environmental Protection Agency (1998). Rout-to-Route Extrapolations. Memorandum from J. E. Whalan and H. M. Pettigrew to M. Stasikowski. Washington, DC: Health Effects Division, Health Effects Division, Office of Pesticide Programs, Office of Prevention, Pesticides, and Toxic Substances.

Vlodavsky, E., Palzur, E., Shehadeh, M., and Soustiel, J. F. (2017). Post-traumatic cytotoxic edema is directly related to mitochondrial function. J. Cereb. Blood Flow Metab. 37, 166-177. doi: 10.1177/0271678X15621068

Wang, G., Yuan, Y., Zhang, J., Gao, L., Tan, X., Yang, G., et al. (2014). Roles of aquaporins and matrix metalloproteinases in mouse brain edema formation induced by subacute exposure to 1,2-dichloroethane. Neurotoxicol. Teratol. 44, 105-112. doi: 10.1016/j.ntt.2014.06.005

Wang, J., Gao, M. L., Shi, Y. T., and Niu, Q. (2007). [Change of neurocytes in acute intoxicated encephalopathy induced by 1,2-dichloroethane after intervention with antagonists]. Zhonghua Lao Dong Wei Sheng Zhi Ye Bing Za Zhi 25, 726-729.

Wang, T., Liao, Y., Sun, Q., Tang, H., Wang, G., Zhao, F., et al. (2017). Upregulation of matrix metalloproteinase- 9 in primary cultured rat astrocytes induced by 2-chloroethanol via MAPK Signal Pathways. Front. Cell. Neurosci. 11:218. doi: 10.3389/fncel.2017.00218

Wells, W. A., and Bonetta, L. (2005). Endothelial tight junctions form the blood-brain barrier. J. Cell Biol. 169:378. doi: 10.1083/jcb1 $693 \mathrm{fta} 1$

Wen, J., Qian, S., Yang, Q., Deng, L., Mo, Y., and Yu, Y. (2014). Overexpression of netrin-1 increases the expression of tight junction-associated proteins, claudin5, occludin, and ZO-1, following traumatic brain injury in rats. Exp. Ther. Med. 8, 881-886. doi: $10.3892 /$ etm.2014.1818

Wolburg, H., Wolburg-Buchholz, K., Kraus, J., Rascher-Eggstein, G., Liebner, S., Hamm, S., et al. (2003). Localization of claudin-3 in tight junctions of the blood-brain barrier is selectively lost during experimental autoimmune encephalomyelitis and human glioblastoma multiforme. Acta Neuropathol. 105, 586-592. doi: 10.1007/s00401-003-0688-Z

Yang, D., Li, S. Y., Yeung, C. M., Chang, R. C., So, K. F., Wong, D., et al. (2012). Lycium barbarum extracts protect the brain from blood-brain barrier disruption and cerebral edema in experimental stroke. PLOS ONE 7:e33596. doi: 10.1371/journal.pone.0033596

Zhang, Q., Niu, Q., Li, L. Y., Yang, L., Guo, X. L., Huang, J. X., et al. (2011). Establishment of a poisoned animal model of toxic encephalopathy induced by 1,2-dichloroethane. Int. J. Immunopathol. Pharmacol. 24(1 Suppl), 79S-83S.

Conflict of Interest Statement: The authors declare that the research was conducted in the absence of any commercial or financial relationships that could be construed as a potential conflict of interest.

Copyright $\odot 2018$ Wang, Yuan, Gao, Tan, Yang, Zhao and Jin. This is an open-access article distributed under the terms of the Creative Commons Attribution License (CC $B Y)$. The use, distribution or reproduction in other forums is permitted, provided the original author(s) or licensor are credited and that the original publication in this journal is cited, in accordance with accepted academic practice. No use, distribution or reproduction is permitted which does not comply with these terms. 